\title{
Designing a database model of district-level land use planning with community consultation in Vung Tau city, Ba Ria - Vung Tau province
}

\author{
Linh D. T. Truong*, \& Thuy T. N. Vo
}

Faculty of Land and Real Estate Management, Nong Lam University, Ho Chi Minh City, Vietnam

\author{
ARTICLE INFO \\ Research Paper \\ Received: June 10, 2021 \\ Revised: July 20, 2021 \\ Accepted: July 27, 2021
}

\section{Keywords}

Community consultation

Database

Land use planning

\section{*Corresponding author}

Truong Do Thuy Linh

\begin{abstract}
Nowadays, building a land database and land use planning database is an indispensable requirement, especially for a seaport city as Vung Tau city (Ba Ria - Vung Tau province) where there are complex land fluctuations. Accordingly, a complete land use planning database with the participation of community will contribute to connecting planners, managers and people, and increase the publicity, transparency and feasibility of land use planning options. The study designed a database model of land use planning with the community consultation for Vung Tau city in accordance with the land data standards of Circular No. 75/2015/TT-BTNMT. Based on the designed model, a set of land use planning database with high accuracy was created and it was in line with the data standards of the Ministry of Natural Resources and Environment and the designed database model. This database structure contained 22 spatial data tables on ArcGIS and 8 attribute data tables (with the community consultation) on Microsoft SQL Sever. Finally, we successfully used the VBDLIS software to build the land use planning database (period 2010 - 2020) for Vung Tau city with 6 data layers, including land use planning data layer (15.060 records), project layer (163 records), adjustment layer for land use planning (12.002 records), adjustment layer for project (570 records), and 2 attribute data layers of community consultation. The results of this study indicated that the correct model and complete database structure were the basis for successfully building and effectively exploiting the database of land use planning. The designed model could contribute to the planning of land management and improve the efficiency of land use.
\end{abstract}

Cited as: Truong, L. D. T., \& Vo, T. T. N. (2021). Designing a database model of district-level land use planning with community consultation in Vung Tau city, Ba Ria - Vung Tau province. The Journal of Agriculture and Development 20(4), 53-68. 


\title{
Nghiên cứu thiết kế mô hình cơ sở dữ liệu quy hoạch sử dụng đất cấp huyện có đề cập đến yếu tố tham vấn cộng đồng tại thành phố Vũng Tàu, tỉnh Bà Rịa - Vũng Tàu
}

\author{
Trương Đỗ Thùy Linh* \& Võ Thị Ngọc Thủy
}

Khoa Quản Lý Đất Đai và Bất Động Sản, Trường Đại Học Nông Lâm TP.HCM, TP. Hồ Chí Minh

\section{THÔNG TIN BÀI BÁO}

Bài báo khoa học

Ngày nhận: 10/06/2021

Ngày chỉnh sửa: 20/07/2021

Ngày chấp nhận: 27/07/2021

\section{Từ khóa}

Cơ sở dữ liệu

Quy hoạch sử dụng đất

Tham vấn cộng đồng

*Tác giả liên hệ

Trương Đỗ Thùy Linh

Email: truongdothuylinh@hcmuaf.edu.vn

\section{TÓM TẮT}

Xây dựng cơ sở dữ liệu (CSDL) đất đai nói chung và CSDL quy hoạch sử dụng đất (QHSDĐ) nói riêng là một yêu cầu tất yếu, nhất là đối với một thành phố cảng biển có mức độ biến động đất đai phức tạp như thành phố Vũng Tàu, tỉnh Bà Rịa - Vũng Tàu. Theo đó, một CSDL QHSDĐ hoàn chỉnh và nhận được sự tham gia góp ý của cộng đồng sẽ góp phần kết nối nhà quy hoạch, nhà quản lý và người dân, giúp tăng tính công khai, minh bạch và tính khả thi của phương án QHSDĐ. Nghiên cứu đã thiết kế được mô hình CSDL QHSDĐ (có đề cập đến yếu tố tham vấn cộng đồng (TVCĐ)) cho TP. Vũng Tàu theo đúng quy chuẩn dữ liệu đất đai của Thông tư 75/2015/TT-BTNMT; từ đó, xây dựng thành công bộ cấu trúc CSDL QHSDĐ có độ chính xác cao, phù hợp với quy chuẩn của ngành và mô hình CSDL đã thiết kế, với 22 bảng dữ liệu không gian trên ArcGIS và 8 bảng dữ liệu thuộc tính (có đề cập đến yếu tố TVCĐ) trên Microsoft SQL Sever. Cuối cùng, đề tài đã thử nghiệm xây dựng thành công CSDL QHSDĐ giai đoạn 2010 - 2020 bằng phần mềm VBDLIS cho TP. Vũng Tàu với 6 lớp dữ liệu gồm: 15.060 bản ghi thuộc lớp QHSDĐ; 163 bản ghi thuộc lớp Công trình dự án; 12.002 bản ghi thuộc lớp Điều chỉnh QHSDĐ; 570 bản ghi thuộc lớp Điều chỉnh công trình dự án và 2 lớp dữ liệu thuộc tính về TVCĐ. Kết quả đạt được cho thấy mô hình và bộ cấu trúc CSDL hoàn chỉnh, đúng quy định chính là cơ sở giúp xây dựng thành công và khai thác hiệu quả CSDL QHSDĐ, góp phần cho việc quản lý đất đai theo quy hoạch và nâng cao hiệu quả sử dụng đất.

\section{1. Đặt Vấn Đề}

Quy hoạch sử dụng đất là quá trình nhằm tạo điều kiện đưa đất đai vào sử dụng bền vững để mang lại lợi ích cao nhất, thực hiện đồng thời hai chức năng điều chỉnh các mối quan hệ đất đai và tổ chức sử dụng dất như tư liệu sản xuất đặc biệt với mục đích nâng cao hiệu quả sản xuất của xã hội, bảo vệ đất đai và môi trường ( $\mathrm{Chu} \&$ ctv., 2020). Tuy nhiên, tại hầu hết các địa phương trên cả nước, trong đó có TP. Vũng Tàu, tỉnh Bà Rịa Vũng Tàu (BR - VT), việc lập và quản lý QHSDĐ tồn tại khá nhiều bất cập, thiếu tính khả thi, tình trạng quy hoạch treo xảy ra phổ biến và thường phải điều chỉnh phương án QHSDĐ. Một trong những nguyên nhân chính là thiếu sự tham gia góp ý và giám sát của cộng đồng vào quá trình lập và quản lý QHSDĐ.

Dưới tác động của cách mạng công nghiệp 4.0, CSDL nói chung và CSDL QHSDĐ nói riêng có vai trò rất đắc lực cho công tác quản lý và giám sát tình hình khai thác, sử dụng đất đai. Đặc biệt, sự kết hợp với hoạt động TVCĐ sẽ góp vai trò rất quan trọng vào quá trình lập, quản lý và quyết định nên chất lượng của phương án QHSDĐ. Đây chính là cơ sở vững chắc để QHSDĐ được triển 
khai đúng, hiệu quả và phù hợp với định hướng phát triển kinh tế - xã hội của quốc gia (Nguyen \& ctv., 2014).

Năm 2015, để quản lý thống nhất dữ liệu đất đai phục vụ tốt nhu cầu của người dân và đáp ứng các mục tiêu phát triển kinh tế - xã hội, Bộ Tài nguyên và Môi trường (TN\&MT) đã ban hành Thông tư 75/2015/TT-BTNMT quy định kỹ thuật về CSDL đất đai, trong đó có quy định về chuẩn CSDL QHSDĐ. Theo đó, cần tổ chức xây dựng mô hình và bộ cấu trúc CSDL QHSDĐ nhằm quản lý thống nhất, đồng bộ CSDL trên phạm vi cả nước; đồng thời, tích hợp thêm một số thông tin liên quan đến yếu tố TVCĐ nhằm hỗ trợ tổng hợp, xử lý, phân tích ý kiến của người dân một cách có hiệu quả; giúp nâng cao tính khả thi của phương án QHSDĐ và giúp việc triển khai, quản lý QHSDĐ được thực hiện dễ dàng, phù hợp hơn với tình hình thực tế.

Xuất phát từ nhu cầu cấp thiết nêu trên, tác giả tiến hành nghiên cứu thiết kế mô hình CSDL QHSDĐ cấp huyện có đề cập đến yếu tố TVCĐ cho TP. Vũng Tàu, tỉnh BR - VT nhằm đáp ứng yêu cầu thực tế trong công tác quản lý đất đai (QLĐĐ) của địa phương và yêu cầu khai thác thông tin đất đai (cụ thể là thông tin QHSDĐ) theo đúng định hướng của Bộ TN\&MT.

\section{Phương Pháp Nghiên Cứu}

Nghiên cứu được thực hiện nhằm thiết kế mô hình và xây dựng bộ cấu trúc CSDL QHSDĐ cấp huyện theo quy chuẩn dữ liệu đất đai của thông tư 75/2015/TT-BTNMT, phục vụ quá trình xây dựng CSDL QHSDĐ cho TP. Vũng Tàu; trong đó có đề cập đến yếu tố TVCĐ nhằm tăng tính công khai, minh bạch và tính khả thi của phương án QHSDĐ. Quy trình thực hiện cụ thể như sau:

Bước 1: Phân tích một số vấn đề liên quan đến TVCĐ trong quản lý nhà nước (QLNN), QLĐĐ và $Q H S D Đ$, làm cơ sở thiết kế mô hình và xây dựng bộ cấu trúc dữ liệu về TVCĐ phù hợp với tình hình lập và quản lý QHSDĐ tại địa phương.

Bước 2: Từ kết quả phân tích về TVCĐ và quy chuẩn dữ liệu đất đai của Thông tư 75/2015/TTBTNMT, tiến hành thiết kế mô hình CSDL QHSDĐ cấp huyện (có đề cập đến yếu tố về TVCĐ); làm cơ sở để xây dựng bộ cấu trúc CSDL QHSDĐ.

Bước 3: Xây dựng bộ cấu trúc CSDL QHSDĐ nhằm mô tả các trường dữ liệu đúng theo quy chuẩn và mô hình CSDL đã thiết kế; trong đó, độ dài trường được khai báo phù hợp, giúp giảm thiểu tối đa độ dư thừa dữ liệu nhưng vẫn thể hiện đầy đủ và tường minh thông tin.

Bước 4: Thử nghiệm xây dựng CSDL QHSDĐ (có đề cập đến yếu tố TVCĐ) cho TP. Vũng Tàu và tham chiếu tới CSDL địa chính giúp quá trình khai thác và truy vấn thông tin QHSDĐ toàn diện và đầy đủ hơn.

Để đạt mục tiêu đề ra, nghiên cứu sử dụng nhiều phương pháp như: Thu thập tài liệu, số liệu (thứ cấp và sơ cấp); Chọn điểm nghiên cứu; Kế thừa; Phỏng vấn chuyên gia; Thiết kế mô hình; Phân tích, thống kê, xử lý số liệu, thông tin; Bản đồ; Ứng dụng công nghệ GIS; Ứng dụng công nghệ thông tin; và Phương pháp xây dựng CSDL QHSDĐ. Trong đó, các phương pháp chính gồm:

Phương pháp phỏng vấn chuyên gia (gồm: phỏng vấn trực tiếp và phỏng vấn qua điện thoại): nghiên cứu phỏng vấn một số lãnh đạo và cán bộ chuyên môn thuộc Tổng cục QLĐĐ; Sở TN\&MT; Văn phòng Đăng ký đất đai tỉnh BR - VT và Văn phòng Đăng ký đất đai các tỉnh Thái Nguyên, Bến Tre... Nội dung phỏng vấn xoay quanh các vấn đề chính như: (1) Thực trạng một số vấn đề liên quan đến TVCĐ trong QLĐĐ và QHSDĐ; (2) Tình hình lập và quản lý QHSDĐ của TP. Vũng Tàu; (3) Thực trạng và hiệu quả sử dụng của nguồn dữ liệu đầu vào phục vụ xây dựng CSDL QHSDĐ trên địa bàn; (4) Tiêu chuẩn, quy trình, quy định xây dựng CSDL QHSDĐ cấp Huyện; (5) Kinh nghiệm và mô hình xây dựng CSDL QHSDĐ tại một số địa phương; và (6) Mức độ đánh giá tính hợp lý về quy hoạch của các loại hình sử dụng đất...

Phương pháp thiết kế mô hình: Được sử dụng trong thiết kế mô hình CSDL QHSDĐ cấp huyện (có đề cập đến yếu tố TVCĐ) cho TP. Vũng Tàu.

Phương pháp ứng dụng công nghệ thông tin: Sử dụng phần mềm Visual Studio trong thiết kế mô hình CSDL và Hệ quản trị Microsoft SQL Server trong xây dựng bộ cấu trúc CSDL QHSDĐ.

Phương pháp ứng dụng GIS: Sử dụng phần mềm ArcGIS trong xây dựng bộ cấu trúc dữ liệu không gian QHSDĐ; và chồng xếp các lớp bản đồ trong phân tích dữ liệu không gian, phi không gian và chuẩn hóa dữ liệu đầu vào phục vụ thử nghiệm xây dựng CSDL QHSDĐ.

Phương pháp xây dựng CSDL QHSDĐ: Sử dụng phần mềm VBDLIS trong thử nghiệm xây dựng CSDL QHSDĐ cho TP. Vũng Tàu (bao gồm: dữ liệu không gian, dữ liệu thuộc tính 
QHSDĐ) và tham chiếu CSDL QHSDĐ tới CSDL địa chính hỗ trợ khai thác và truy vấn thông tin QHSDĐ được toàn diện và đầy đủ hơn.

\section{Kết Quả và Thảo Luận}

3.1. Phân tích một số vấn đề liên quan đến tham vấn cộng đồng trong quản lý đất đai và quy hoạch sử dụng đất

\subsubsection{Tham vấn cộng đồng trong quản lý nhà nước}

Theo MOHA (2016), 4 hình thức TVCĐ phổ biến gồm: (1) Lấy đối thoại bình đẳng làm mục đích, (2) Tham gia nhằm mục đích tiếp nhận thông tin cho quá trình hoạch định và thực thi chính sách, (3) Tham gia nhằm mục đích tăng cường sự ủng hộ của người dân đối với chính sách, (4) Lấy phát triển và tăng cường năng lực tự quản của người dân làm mục đích.

Thời gian qua, TVCĐ trong QLNN bộc lộ khá nhiều ưu điểm như: (1) Góp phần thực hiện quyền và phát triển năng lực của công dân; (2) Bồi dưỡng năng lực kiểm soát chính trị và tăng cường tình cảm, hiệu quả chính trị của công dân; (3) Đóng góp quan trọng vào sự ổn định, phát triển xã hội; thúc đẩy thực hiện công bằng xã hội và tích hợp được các nguồn lực trong xã hội; (4) Đóng góp quan trọng cho hệ thống chính trị, giúp tăng cường sự ủng hộ và niềm tin của người dân đối với các cơ quan nhà nước nhờ gia tăng độ công khai, minh bạch trong hoạt động của các cơ quan này.

Tuy nhiên, TVCĐ trong QLNN vẫn tồn tại một số hạn chế: (1) Hình thức và công cụ hỗ trợ người dân tham gia TVCĐ chưa đa dạng và phổ biến; (2) Do hạn chế về nhận thức và trình độ, người dân chưa thấy hết quyền lợi và nghĩa vụ khi tham gia QLNN, chưa làm hết sức mình khi tham gia bầu cử; (3) Hình thức tham gia thông qua các tổ chức chính trị - xã hội mà người dân là thành viên còn hạn chế; (4) Quyền quyết định các vấn đề hệ trọng của đất nước thông qua trưng cầu dân ý và trực tiếp quyết định nhiều vấn đề liên quan đến đời sống ở cơ sở của người dân chưa được thực hiện triệt để, vừa hạn chế quyền tham gia QLNN của người dân, không huy động được sức mạnh của nhân dân trong quản lý, phát triển kinh tế - xã hội địa phương; vừa là căn nguyên của các vụ khiếu kiện kéo dài tại cơ sở; (5) Việc người dân kiểm tra, giám sát và khiếu nại, tố cáo những việc làm trái pháp luật trong hoạt động QLNN của cơ quan và công chức nhà nước còn rất hạn chế.

\subsubsection{Tham vấn cộng đồng trong quản lý đất đai và quy hoạch sử dụng đất}

Trong QLĐĐ tại Việt Nam, quy chế dân chủ cơ sở đang từng bước được cư thể hoá thông qua TVCĐ và tạo điều kiện để cộng đồng tham gia vào các hoạt động QLĐĐ. Theo OIV (2013), TVCĐ trong QLĐĐ thể hiện tại các nội dung: (1) TVCĐ trong xây dựng và hoàn thiện chính sách pháp luật đất đai sát với thực tiễn, phù hợp với lợi ích của Nhà nước, cộng đồng; (2) TVCĐ trong lập và tổ chức thực hiện QHSDĐ sát với thực tế, nâng cao chất lượng dự báo và tính khả thi; (3) TVCĐ về giao đất, cho thuê đất, thu hồi đất, bồi thường hỗ trợ và tái định cư; (4) TVCĐ về đăng ký đất đai, cấp Giấy chứng nhận, thúc đẩy cải cách hành chính trong lĩnh vực đất đai, giúp cho hệ thống hoạt động công khai, minh bạch, hiệu quả; (6) TVCĐ trong thanh tra, kiểm tra, hòa giải, giải quyết khiếu nại, tố cáo trong lĩnh vực quản lý, sử dụng đất đai.

Hiện phương thức quản lý dựa vào cộng đồng trong QLĐĐ (Hình 1) được phân thành các cấp độ sau: (1) Cấp độ thông báo: Nhà nước ra quyết định, thông báo và hướng dẫn cộng đồng tham gia quản lý; (2) Cấp độ tham vấn: Cộng đồng được cung cấp thông tin, Nhà nước tham khảo ý kiến của động đồng trong việc ra quyết định, thông báo và hướng dẫn cộng đồng tham gia quản lý; (3) Cấp độ hợp tác: Nhà nước và cộng đồng có vai trò ngang nhau trong việc đưa ra quyết định cuối cùng về kế hoạch quản lý tài nguyên đất đai; (4) Cấp độ tự quản lý: Cộng đồng được Nhà nước trao toàn quyền quản lý tài nguyên, Nhà nước chỉ thực hiện kiểm soát.

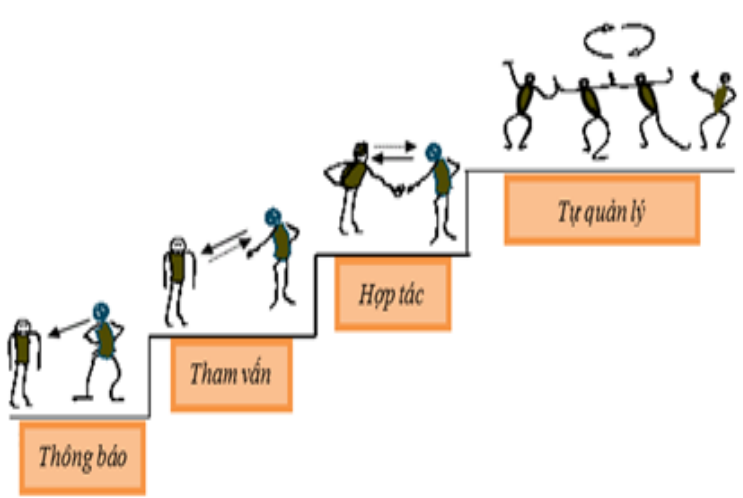

Hình 1. Mô hình 4 cấp độ quản lý dựa vào cộng đồng trong quản lý đất đai. 
Tham vấn cộng đồng trong QLĐĐ và $\mathrm{QHSDĐ}$ gặp một số thuận lợi sau: (1) Đa phần công chúng ủng hộ quan điểm của Nhà nước về xây dựng "Xã hội công bằng, dân chủ, văn minh" và khuyến khích chủ trương "Dân biết, dân bàn, dân làm, dân kiểm tra" trong mọi hoạt động của các tổ chức chính trị, kinh tế - xã hội; (2) Tổ chức bộ máy của Việt Nam thuận lợi cho việc phát huy vai trò của các tổ chức chính trị - xã hội - nghề nghiệp trong quá trình chuẩn bị chính sách, quy hoạch, triển khai dự án, báo cáo và thẩm định dự án; (3) Phần lớn người dân mong muốn được nhận thông tin công khai từ chính sách, quy hoạch, dự án và được tham gia ý kiến đối với chính sách, quy hoạch, dự án ở địa phương; (4) Cơ chế công bố thông tin giúp giảm nhẹ áp lực của các cấp quản lý trong việc tuân thủ các thủ tục cần thiết trong quá trình ra quyết định; (5) Thông qua sự tham gia của cộng đồng các chủ đầu tư bắt buộc phải có trách nhiệm hơn với những vấn đề liên quan đến môi trường của dự án, chính sách và quy hoạch (Nguyen, 2015).

Bên cạnh đó, còn tồn tại một số hạn chế: (1) Tính minh bạch trong quá trình lập, quản lý QHSDĐ và triển khai công trình, dự án chưa được quan tâm triệt để; (2) Các đơn vị tư vấn thực hiện dự án không tự nguyện thực hiện TVCĐ vì ngại chỉnh sửa phương án, nghiên cứu bổ sung; (3) Kinh phí thực hiện dự án không có mục chi cho TVCĐ; (4) Nhiều tổ chức và người dân chưa chủ động tham gia góp ý cho các dự án, chính sách và quy hoạch nếu không được cơ quan có thẩm quyền mời họp hoặc xin ý kiến; (5) TVCĐ có thể dẫn đến những điều không chắc chắn về kết quả của quá trình công khai thông tin, khiến dự án bị chậm hoặc tốn kém hơn dự tính; (6) Thời gian lập và thẩm định phương án QHSDĐ khá ngắn nên khó có thể triển khai TVCĐ.

Tóm lại, cần phải ban hành quy định về tham vấn cộng đồng trong quản lý dất đai, đặc biệt trong QHSDĐ và cần có những cơ chế để cộng đồng và các tổ chức chính trị, kinh tế - xã hội tham gia đối thoại, đóng góp ý kiến trong quá trình ra quyết định; đồng thời, giám sát, theo dõi và đánh giá việc quản lý, sử dụng đất thông qua TVCĐ. Như vậy, việc thực hiện tham vấn cộng đồng không chỉ là quyền mà còn là cơ hội để người dân đóng góp nhiều hơn cho cộng đồng và công tác QLNN, giúp nâng cao mức độ tín nhiệm trong nhân dân và tăng cường hiệu lực, hiệu quả công tác quản lý đất đai, trong đó có công tác lập quản lý quy hoạch sử dụng đất.

\subsection{Thiết kế mô hình cơ sở dữ liệu quy hoạch sử dụng đất đai cấp huyện (có đề cập đến yếu tố tham vấn cộng đồng)}

Để xây dựng, quản lý, khai thác và chia sẻ hiệu quả dữ liệu QHSDĐ, đề tài thiết kế mô hình CSDL QHSDĐ gồm 2 nhóm đối tượng (kèm theo các chú thích về sự liên kết dữ liệu giữa các nhóm, Hình 2) đó là: CSDL không gian QHSDĐ và CSDL thuộc tính QHSDĐ (có đề cập đến yếu tố TVCĐ); sau đó, tham chiếu tới CSDL địa chính của TP. Vũng Tàu nhằm khai thác và truy vấn thông tin QHSDĐ được toàn diện và đầy đủ hơn, đáp ứng nhu cầu của cơ quan, đơn vị, người dân và doanh nghiệp trong giao dịch đất đai và tra cứu thông tin QHSDĐ.

\subsubsection{Thiết kế mô hình cơ sở dữ liệu không gian quy hoạch sử dụng đất cấp huyện}

Theo MONRE (2015), trong CSDL không gian đất đai, CSDL không gian đất đai nền có vai trò rất quan trọng, làm cơ sở và định vị không gian cho các CSDL không gian đất đai chuyên đề thuộc CSDL đất đai, bao gồm cả CSDL không gian chuyên đề QHSDĐ. Do vậy, để CSDL QHSDĐ TP. Vũng Tàu được xây dựng hoàn chỉnh và vận hành hiệu quả, cần liên kết chặt chẽ CSDL này với CSDL không gian đất đai nền. Theo Hình 2, mô hình CSDL QHSDĐ được thiết kế trên cơ sở tham chiếu CSDL QHSDĐ tới CSDL không gian đất đai nền bằng các quan hệ không gian; đồng thời, liên kết với CSDL thuộc tính QHSDĐ bằng khóa liên kết và mã đối tượng đồ họa phục vụ tra cứu thông tin không gian và thuộc tính đồng thời trên cùng một môi trường thống nhất.

Mô hình CSDL không gian QHSDĐ được thiết kế bằng phần mềm Visual Studio (Hình 4). Trong đó, quan hệ giữa các thực thể được biểu diễn dưới dạng sơ đồ lớp (Class Diagram), mỗi thực thể trong sơ đồ được mô tả là một hình chữ nhật gồm 2 phần: phần phía trên là tên của lớp, phần phía dưới là thuộc tính của lớp đó; ngoài ra, mỗi lớp còn thể hiện các khả năng truy xuất thông tin đối tượng, bao gồm: private (thông tin bị che giấu hoàn toàn), protected (chỉ che giấu với đối tượng bên ngoài), và public (cho phép tất cả mọi dối tượng truy xuất); đồng thời, mối quan hệ giữa các thực thể còn được xác định bằng các giá trị bội số, bao gồm: $0 . .1$ (có giá trị là 1 hoặc 0$), 1$ (chỉ có giá trị là 1$),^{*}$ (có nhiều giá trị), 1..* (có giá trị là 1 hoặc nhiều hơn). Từ đó, mô hình CSDL không gian QHSDĐ cấp huyện của TP. Vũng Tàu 


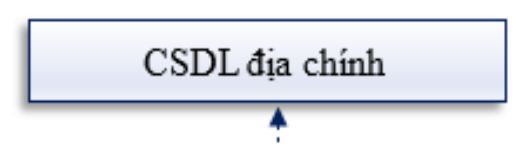

Tham chiều

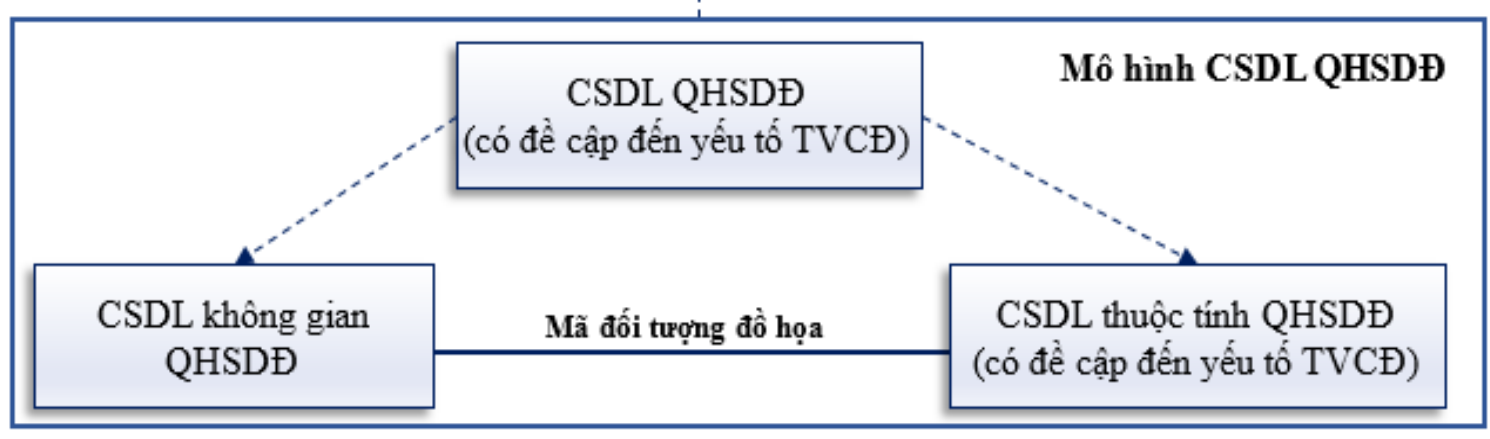

Hình 2. Mô hình cơ sở dữ liệu quy hoạch sử dụng đất (có đề cập đến yếu tố tham vấn cộng đồng).

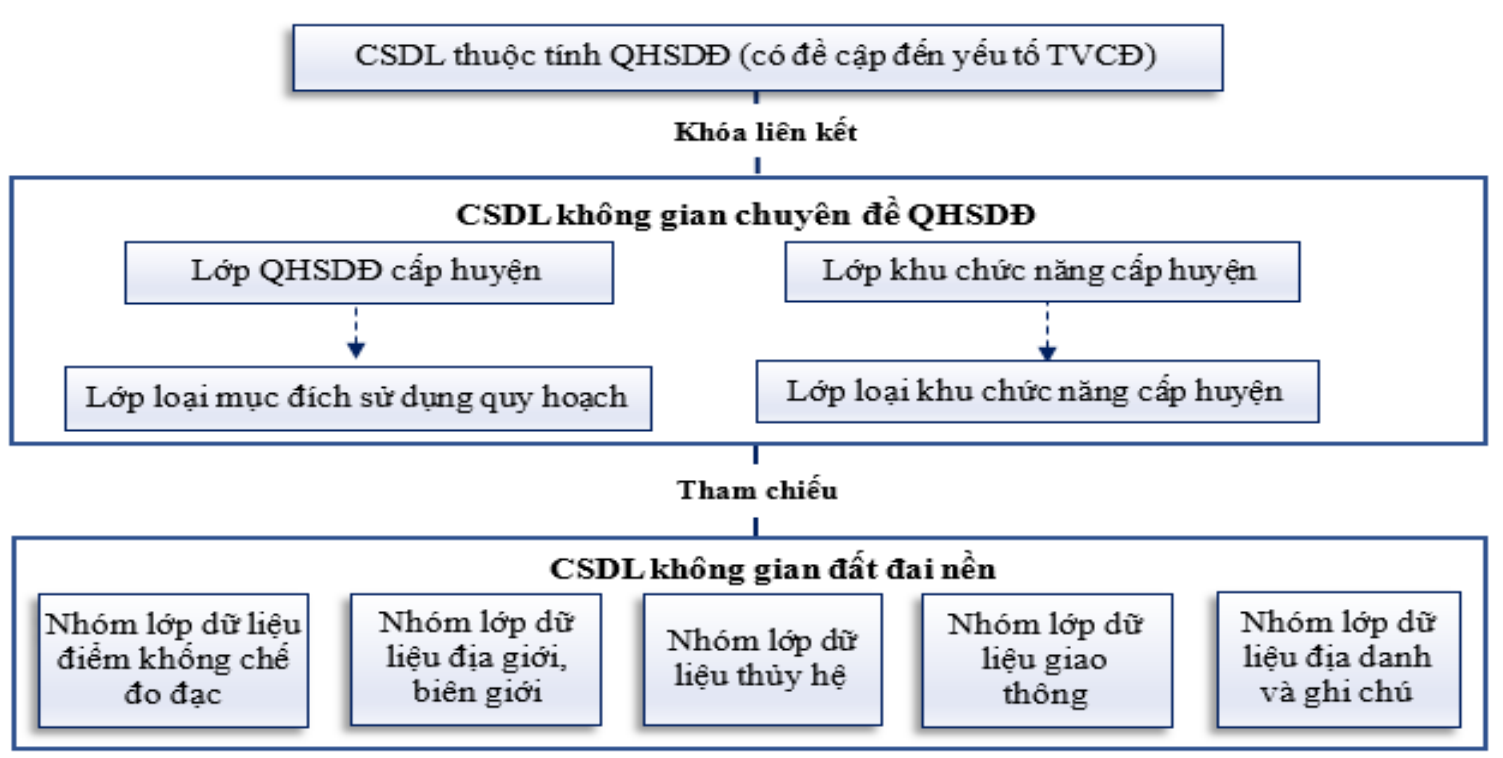

Hình 3. Mô hình liên kết cơ sở dữ liệu không gian quy hoạch sử dụng đất với cơ sở dữ liệu không gian đất đai nền.

gồm 4 thực thể (Hình 4).

3.2.2. Thiết kế mô hình cơ sở dữ liệu thuộc tính quy hoạch sử dụng đất cấp huyện (có đề cập đến yếu tố tham vấn cộng đồng)

Quản lý đất đai nói chung và QHSDĐ nói riêng sẽ đạt hiệu quả cao hơn nếu có sự tham gia của cộng đồng. Trong đó, ý kiến phản ánh và sự đồng thuận của người dân có vai trò rất quan trọng đối với tiến độ thực hiện các công trình dự án và tính khả thi của phương án QHSDĐ. Theo đó, ngoài các lớp dữ liệu chuẩn theo quy định, đề tài thiết

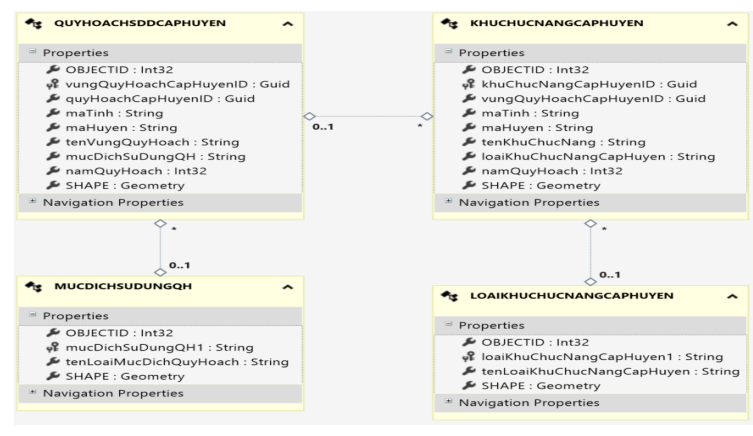

Hình 4. Mô hình cơ sở dữ liệu không gian quy hoạch sử dụng đất. 
kế thêm Nhóm lớp dữ liệu TVCĐ trong QHSDĐ nhằm tổng hợp, xử lý và phản hồi lại ý kiến của người dân về việc lập và quản lý quy hoạch sử dụng đất.

Người dân có thể đóng góp ý kiến để cơ quan Nhà nước tổng hợp thông tin cho lớp dữ liệu này bằng nhiều cách, bao gồm: đóng góp ý kiến trực tiếp qua hình thức tổ chức hội nghị; và đóng góp ý kiến gián tiếp thông qua cổng thông tin điện tử của Ủy ban nhân dân Tỉnh, Thành phố. Ngoài ra, cơ quan Nhà nước cũng có thể thu thập thông tin cho lớp dữ liệu tham vấn cộng đồng thông qua hình thức lấy ý kiến trực tiếp thông qua việc phát phiếu điều tra - khảo sát đến từng hộ dân bị ảnh hưởng bởi phương án quy hoạch sử dụng đất (NA, 2018).

Trên cơ sở ý kiến thu thập được, bộ phận chịu trách nhiệm sẽ tiến hành thống kê các thông tin TVCĐ bằng cách nhập các thông tin thu thập được từ hình thức điều tra trực tiếp vào phần mềm quản lý CSDL quy hoạch sử dụng đất; đồng thời, đồng bộ với nhóm thông tin do người dân đóng góp gián tiếp thông qua các cổng thông tin đất đai. Từ đó, tiến hành phân tích, tổng hợp và xử lý thông tin bằng nhiều phương pháp định tính và định lượng khác nhau nhằm đưa ra được bức tranh phản ánh toàn diện nhất mức độ đồng thuận và ý kiến đóng góp của người dân về quá trình lập và quản lý quy hoạch sử dụng đất tại địa phương, để có cơ sở tham mưu cơ quan có thẩm quyền điều chỉnh phương án quy hoạch sử dụng đất phù hợp; song song đó, phản hồi thông tin kịp thời đến người dân để cộng đồng yên tâm và tin tưởng vào bộ máy và hệ thống chính trị của Nhà nước.

Đây chính là kênh thông tin cho phép đối tượng tham gia tham vấn cho điểm và đánh giá tính hợp lý về quy hoạch của các loại hình sử dụng đất khác nhau. Dựa trên kết quả tham vấn ý kiến chuyên gia tại Tổng cục quản lý đất đai, VP đăng ký đất đai và Sở Tài nguyên \& Môi trường tỉnh Bà Rịa - Vũng Tàu, tác giả chia thành 4 mức độ đánh giá gồm: rất không hợp lý, không hợp lý, hợp lý và rất hợp lý. Thông tin thu thập được từ nhóm lớp dữ liệu này sẽ giúp tăng hiệu quả và tính khả thi của phương án QHSDĐ, tăng mức độ tín nhiệm của người dân đối với cơ quan Nhà nước cũng như góp phần ổn định và phát triển kinh tế - xã hội.

Tương tự mô hình CSDL không gian, mô hình CSDL thuộc tính QHSDĐ (có đề cập đến yếu tố tham vấn cộng đồng) của TP. Vũng Tàu cũng được thiết kế bằng Visual Studio, gồm 8 thực thể (Hình 5).

Nhận xét chung: Thông qua việc thiết kế mô hình CSDL, các thực thể trong CSDL quy hoạch sử dụng đất được thể hiện rõ ràng hơn; đồng thời, các mối quan hệ giữa chúng được biểu diễn chặt chẽ hơn nhờ các quan hệ liên kết một - nhiều (1-*) và liên kết không/một - nhiều $\left(0 . .1\right.$ - * $\left.^{*}\right)$ và cấu trúc CSDL được thể hiện rõ hơn ứng với từng trường dữ liệu cư thể. Điều này giúp quá trình liên kết và truy xuất dữ liệu giữa các bảng được thực hiện khoa học, tường minh, nhanh chóng và chính xác hơn. Đây chính là cơ sở giúp xây dựng thành công và khai thác hiệu quả CSDL quy hoạch sử dụng đất (có đề cập đến yếu tố TVCĐ) cho TP. Vũng Tàu sau này.

\subsection{Xây dựng bộ cấu trúc cơ sở dữ liệu quy hoạch sử dụng đất cấp huyện (có đề cập đến yếu tố tham vấn cộng đồng)}

Theo Truong (2021), cấu trúc dữ liệu là cách lưu trữ, tổ chức dữ liệu có thứ tự, có hệ thống để dữ liệu được khai thác, sử dụng một cách hiệu quả. Vì vậy, cần thiết phải xây dựng bộ cấu trúc dữ liệu cho CSDL quy hoạch sử dụng đât TP. Vũng Tàu theo đúng thiết kế và quy chuẩn của ngành nhằm xây dựng thành công và khai thác hiệu quả cơ sở dữ liệu quy hoạch sử dụng dất; đồng thời, đồng bộ với CSDL của cả nước, góp phần xây dựng hoàn chỉnh CSDL đất đai quốc gia.

\subsubsection{Xây dựng bộ cấu trúc cơ sở dữ liệu không gian quy hoạch sử dụng đất trên phần mềm ArcGIS}

Bộ cấu trúc cơ sở dữ liệu không gian đất đai nền và không gian chuyên đề quy hoạch sử dụng đất cấp huyện được xây dựng theo bằng phần mềm ArcGIS (Hình 6A).

Đề tài đã xây dựng được bộ cấu trúc cơ sở dữ liệu không gian quy hoạch sử dụng đất theo đúng Thông tư 75/2015/TT-BTNMT và kết nối thành công với CSDL thuộc tính quy hoạch sử dụng đất trên MS SQL Server với 18 bảng thuộc 5 nhóm lớp dữ liệu của CSDL không gian đất đai nền và 4 bảng thuộc 2 lớp dữ liệu của CSDL không gian chuyên đề quy hoạch sử dụng đất (Hình 7); đồng thời, xây dựng được sơ đồ quan hệ thể hiện rõ mối liên kết giữa các bảng dữ liệu thông qua quan hệ không gian và các khóa liên kết, phục vụ tốt cho quá trình xây dựng cơ sở dữ liệu quy hoạch sử 


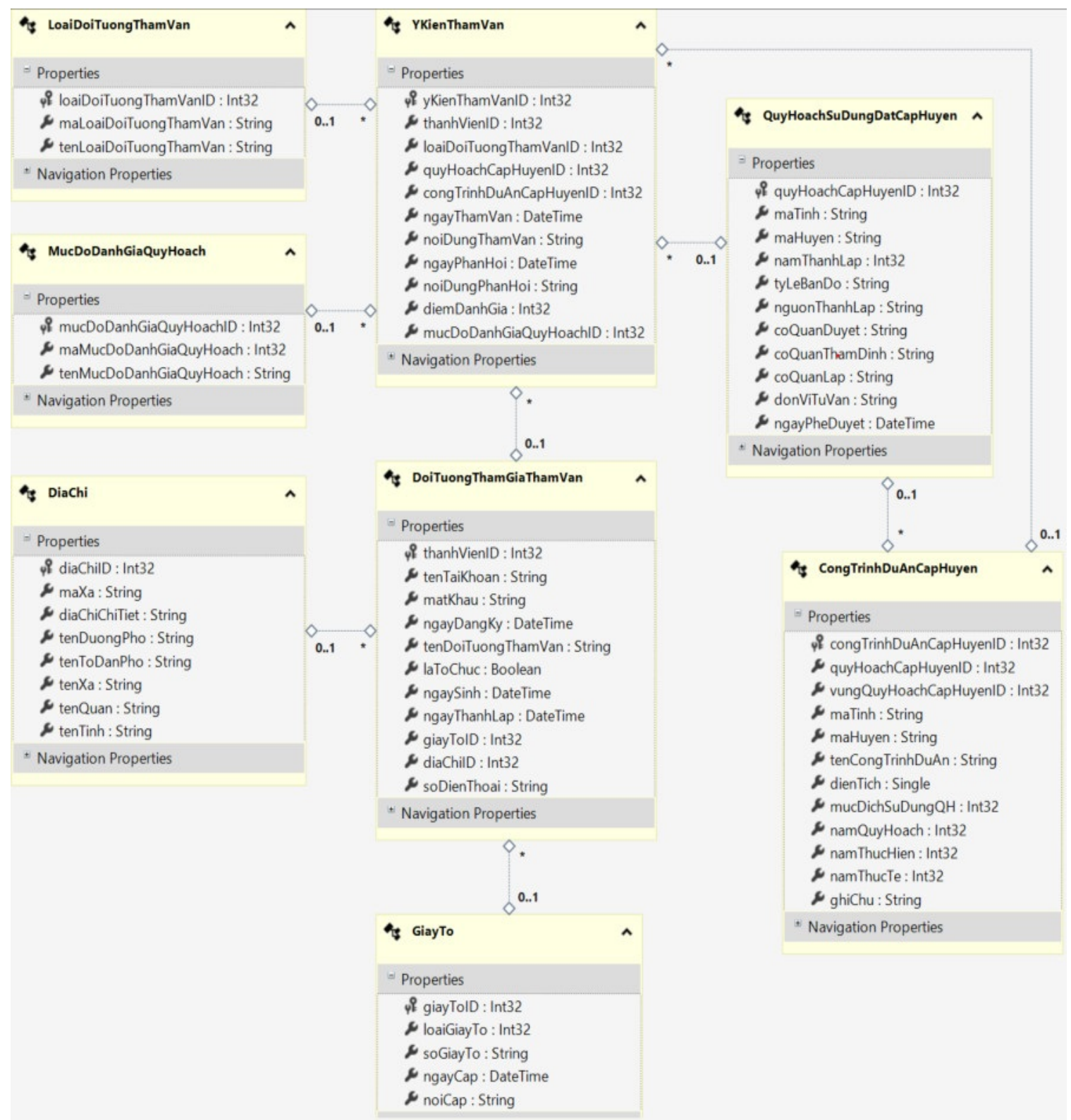

Hình 5. Mô hình cơ sở dữ liệu thuộc tính quy hoạch sử dụng đất cấp huyện (có đề cập đến yếu tố tham vấn cộng đồng).

dụng đất của địa phương.

3.3.2. Xây dựng bộ cấu trúc cơ sở dữ liệu thuộc tính quy hoạch sử dụng đất (có đề cập đển yếu tố tham vấn cộng đồng) trên hệ̣ quản trị Microsoft SQL Sever

Bộ cấu trúc CSDL thuộc tính QHSDĐ được xây dựng theo Hình $6 \mathrm{~B}$ bằng Hệ quản trị CSDL Microsoft SQL Server (LeBlanc, 2013).

Bộ cấu trúc dữ liệu thuộc tính QHSDĐ (có đề cập đến yếu tố TVCĐ) được định nghĩa với 8 bảng dữ liệu gồm: 2 bảng dữ liệu thuộc nhóm QHSDĐ và 6 bảng dữ liệu thuộc nhóm TVCĐ. Bộ cấu trúc này được xây dựng và định nghĩa chính xác, đúng kiểu dữ liệu theo mô hình thiết kế và quy định tại thông tư 75/2015/TT/BTNMT. Do đó, các bảng dữ liệu được tạo ra đảm bảo được tính đầy đủ và chính xác, giúp cho việc liên kết dữ liệu giữa các bảng được dễ dàng và thuận tiện hơn. Ngoài ra, đề tài đã xác định và xây dựng 


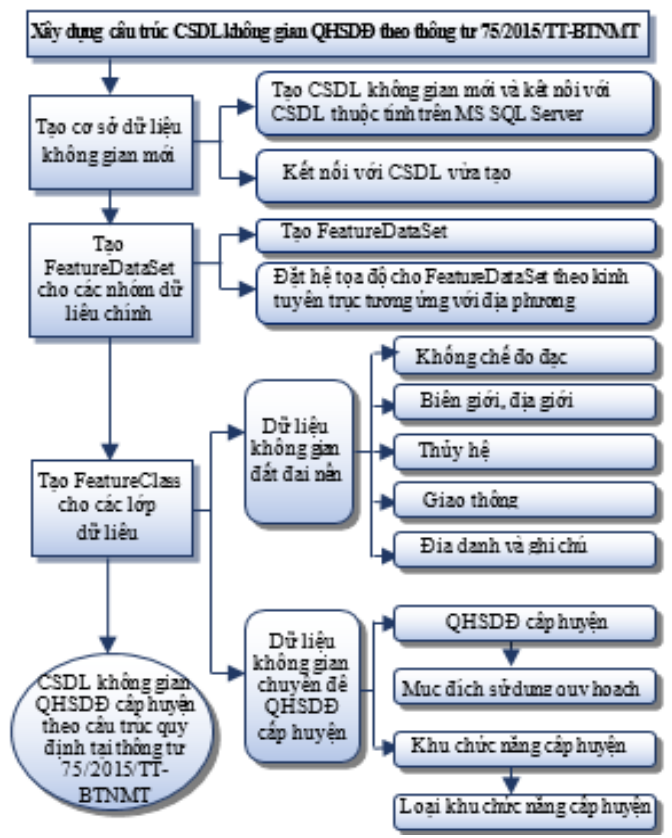

(A)

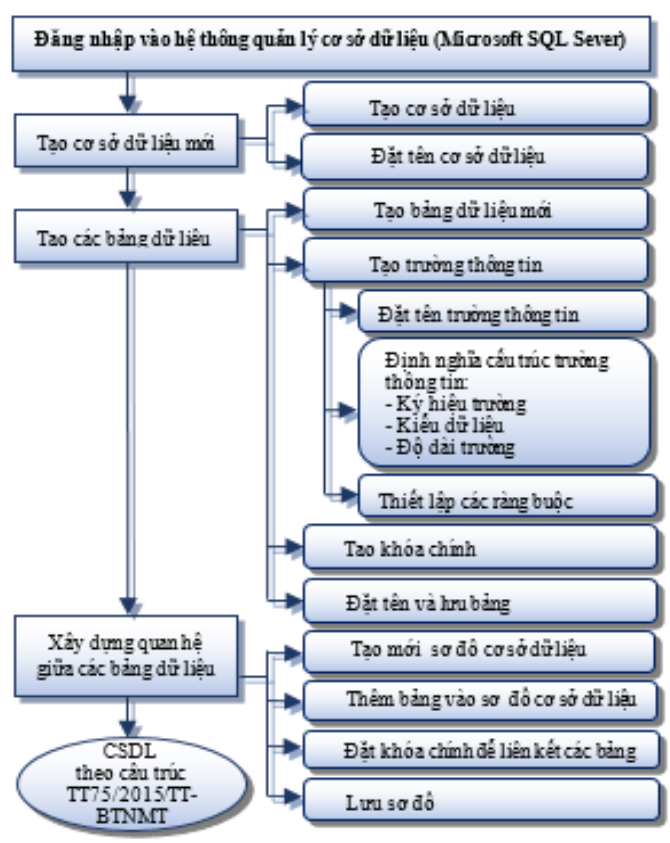

(B)

Hình 6. Quy trình xây dựng bộ cấu trúc cơ sở dữ liệu không gian quy hoạch sử dụng đất cấp huyện (A) và thuộc tính quy hoạch sử dụng đất cấp huyện $(B)$.
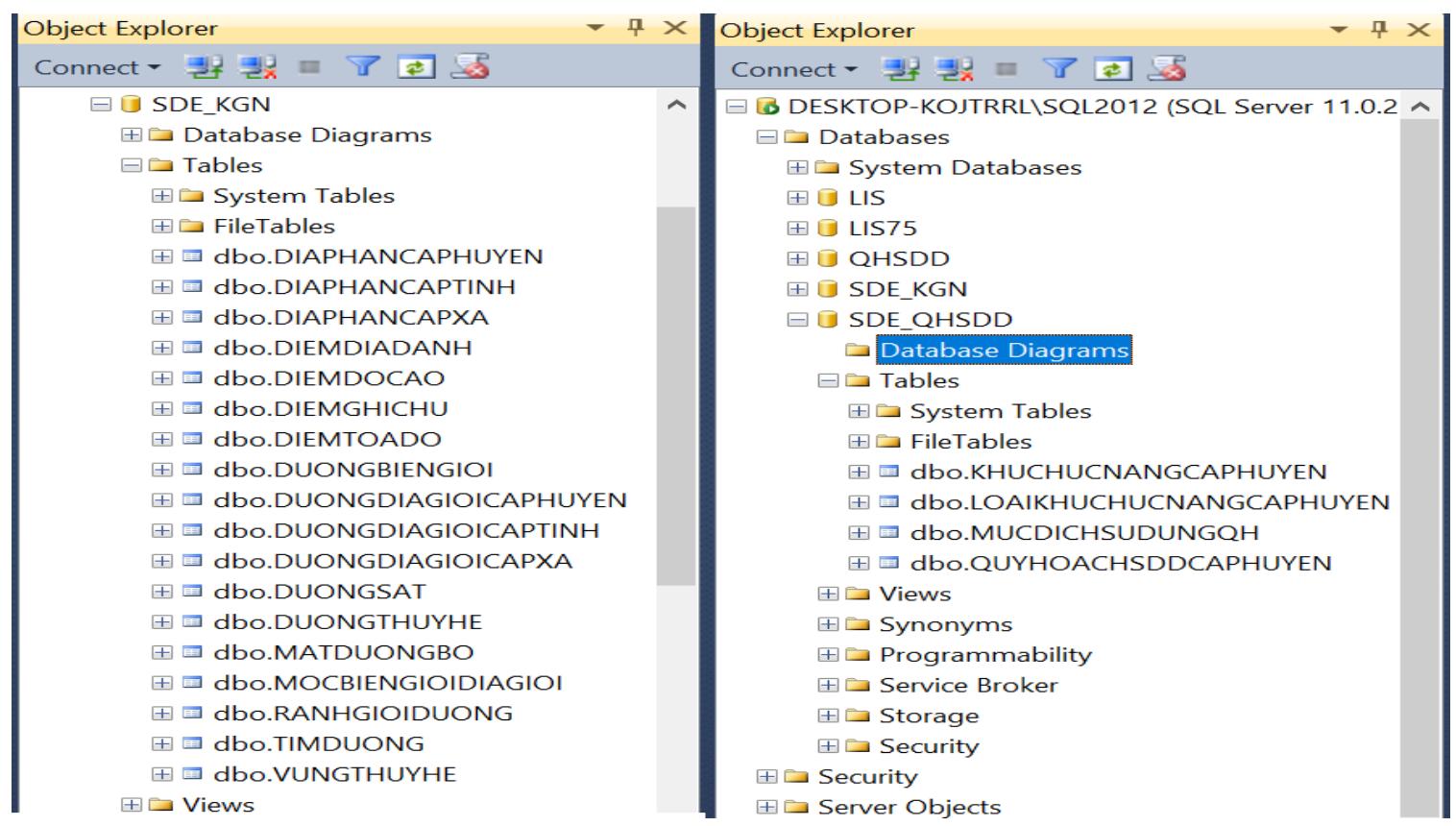

Hình 7. Kết quả kết nối thành công cơ sở dữ liệu không gian quy hoạch sử dụng đất trên MS SQL Server.

thành công sơ đồ quan hệ giữa các bảng dữ liệu thông qua các khóa chính và khóa ngoại, giúp các bảng dữ liệu được kết nối và ràng buộc với nhau chặt chẽ hơn (Hình 8).
Nhận xét chung: Bộ cấu trúc CSDL QHSDĐ có độ chính xác cao và hoàn toàn phù hợp với quy chuẩn của Thông tư 75/2015/TT-BTNMT và mô hình CSDL đã được thiết kế. Theo đó, CSDL 


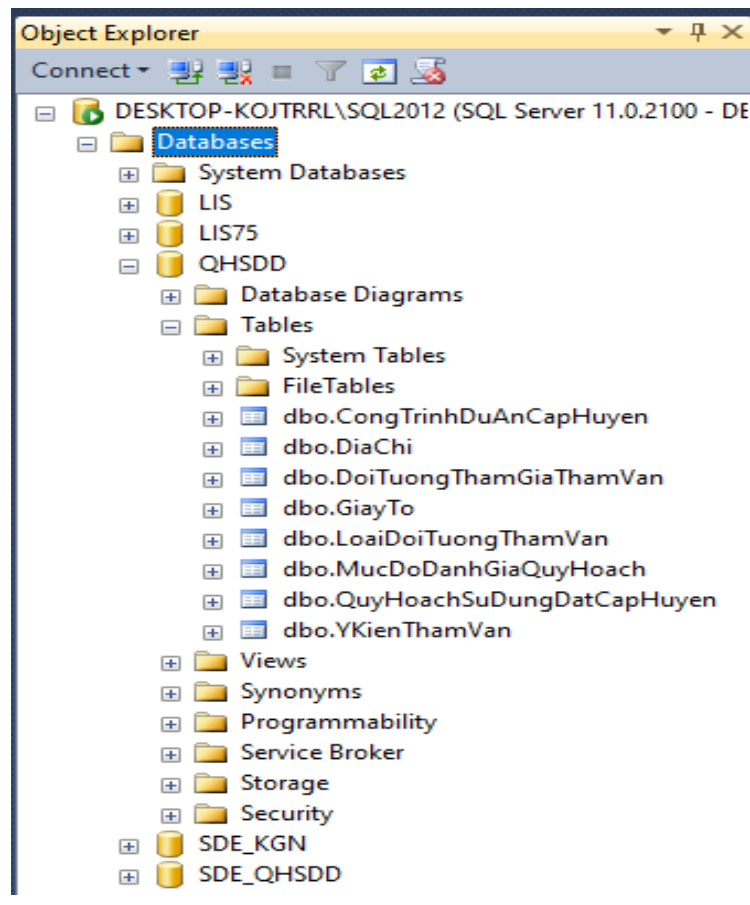

Hình 8. Kết quả tạo bảng dữ liệu thuộc tính quy hoạch sử dụng đất trên MS SQL Server.

QHSDĐ sẽ được xây dựng trên nền CSDL không gian đất đai nền; được tham chiếu đến CSDL địa chính; và được tích hợp với các bảng dữ liệu hỗ trợ tổng hợp và xử lý ý kiến TVCĐ về quá trình lập - quản lý QHSDĐ, đáp ứng yêu cầu đánh giá quy hoạch, phản hồi thông tin,... góp phần tăng tính khả thi cho phương án QHSDĐ cũng như tăng tính minh bạch trong thị trường đất đai và bất động sản.

3.4. Xây dựng, quản lý, cập nhật, chia sẻ và khai thác cơ sở dữ liệu quy hoạch sử dụng đất (có đề cập đến yếu tố tham vấn cộng đồng) cho TP. Vũng Tàu

3.4.1. Xây dựng cơ sở dữ liệu quy hoạch sử dụng đất

\section{a. Đánh giá nguồn dữ liệu đầu vào}

Nguồn dữ liệu QHSDĐ đầu vào của TP. Vũng Tàu gồm: dữ liệu QHSDĐ (giai đoạn 2010 - 2020) và dữ liệu điều chỉnh QHSDĐ (giai đoạn 2016 2020), cụ thể:

Nguồn dữ liệu không gian gồm: bản đồ QHSDĐ và bản đồ điều chỉnh QHSDĐ, được lập dưới dạng *.dgn, hệ tọa độ VN - 2000, tỷ lệ 1:10.000; thông tin và đối tượng trên bản đồ được thể hiện khá đầy đủ, chi tiết, rõ ràng giúp người dùng dễ dàng tra cứu và truy xuất thông tin.

Nguồn dữ liệu thuộc tính: các thông tin (năm thành lập, tỷ lệ bản đồ, cơ quan có thẩm quyền phê duyệt bản đồ QHSDĐ,... . ) được thể hiện đầy đủ, rõ ràng, hỗ trợ tốt cho việc xây dựng CSDL; các công trình, dự án QHSDĐ được thể hiện chi tiết, giúp quá trình xây dựng CSDL QHSDĐ được hoàn chỉnh, người dùng dễ dàng khai thác, truy cập và tra cứu thông tin hiệu quả.

Tóm lại, nguồn dữ liệu này cơ bản đáp ứng yêu cầu xây dựng CSDL QHSDĐ, các thông tin được thể hiện đầy đủ, rõ ràng, đúng với quy định của thông tư 29/2014/TT-BTNMT, phù hợp với chuẩn dữ liệu của thông tư 75/2015/TTBTNMT. Tuy nhiên, để đảm bảo chất lượng và tính chính xác của CSDL QHSDĐ, nguồn dữ liệu này cần được chuẩn hóa trước khi được đưa vào xây dựng thử nghiệm CSDL QHSDĐ cho TP. Vũng Tàu.

\section{b. Chuẩn hóa nguồn dữ liệu đầu vào}

Đề tài đã sử dụng phần mềm MicroStation và ArcGIS để kiểm tra, rà soát, chuẩn hóa nguồn dữ liệu đầu vào (gồm 2 lớp dữ liệu: QHSDĐ và điều chỉnh QHSDĐ) trước khi đưa vào xây dựng CSDL nhằm vận hành và khai thác CSDL QHSDĐ một cách hiệu quả nhất (Hình 9).

\section{c. Xây dựng cơ sở dữ liệu quy hoạch sử} dụng đất

Nghiên cứu thực hiện chuyển đổi Bộ cấu trúc CSDL QHSDĐ đã xây dựng vào Phần mềm VBDLIS và sử dụng phần mềm này thử nghiệm xây dựng thành công CSDL QHSDĐ theo đúng quy chuẩn dữ liệu của Thông tư 75/2015/TTBTNMT và mô hình CSDL đã thiết kế. Kết quả đã xây dựng được các lớp dữ liệu gồm: (1) Lớp QHSDĐ với 15.060 bản ghi; (2) Lớp Công trình dự án với 163 bản ghi; (3) Lớp Điều chỉnh QHSDĐ với 12.002 bản ghi; (4) Lớp Điều chỉnh công trình dự án điều chỉnh với 570 bản ghi; đồng thời, tạo được 2 lớp dữ liệu phục vụ tổng hợp và xử lý ý kiến đóng góp của cộng đồng về QHSDĐ là: Lớp đối tượng tham gia tham vấn và Lớp ý kiến tham vấn (Hình 10).

d. Tham chiếu cơ sở dữ liệu quy hoạch sử dụng đất với cơ sở dữ liệu địa chính

Đề tài tham chiếu thử nghiệm CSDL QHSDĐ vừa tạo tới CSDL địa chính của Phường $8, T$ P. Vũng Tàu (Hình 11). Theo đó, ngoài thông tin về QHSDĐ như đã thiết kế ở trên, người dùng có thể tra cứu thêm các thông tin về địa chính của 


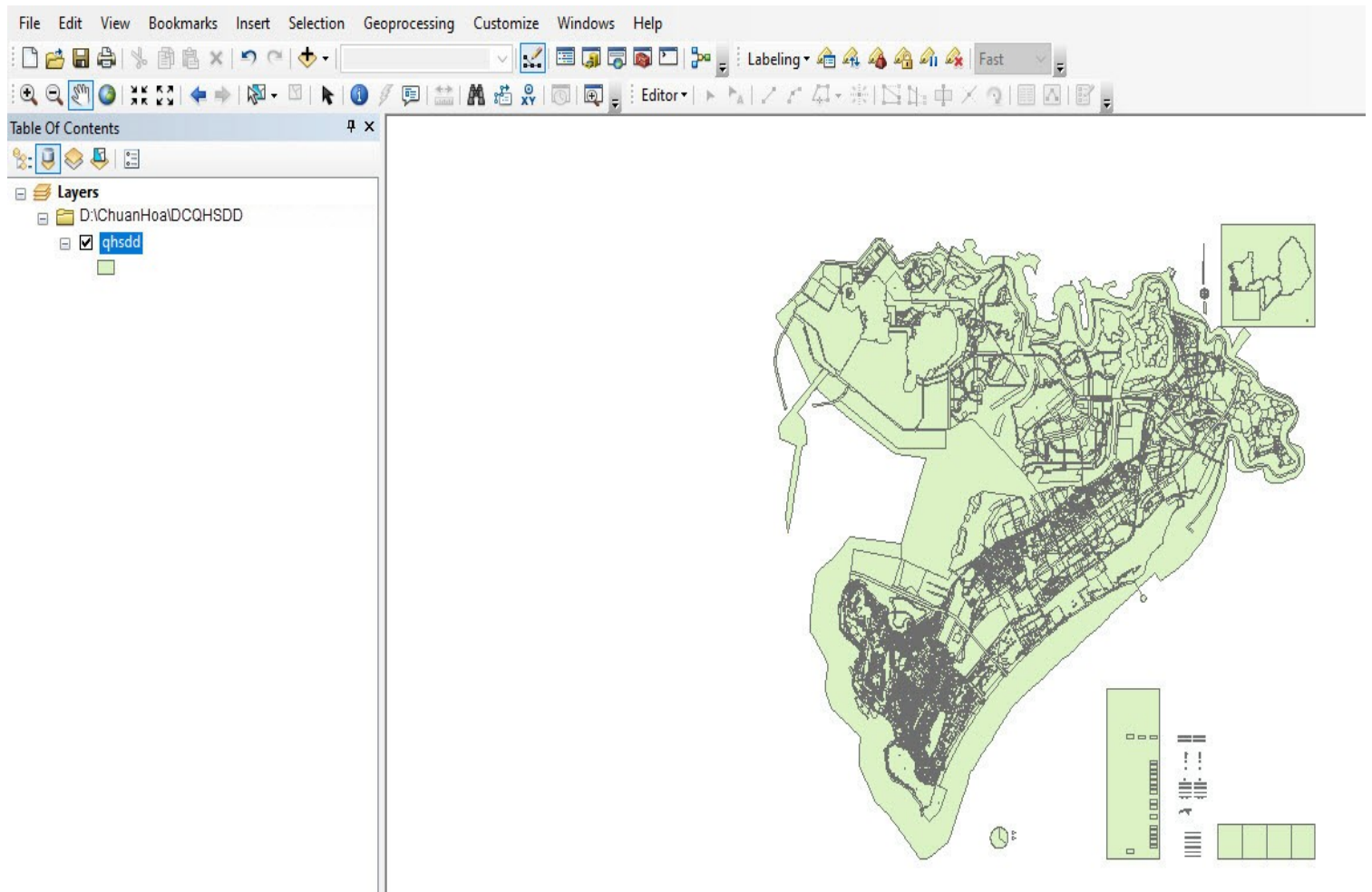

Hình 9. Kết quả chuẩn hóa dữ liệu đầu vào trên ArcGIS.

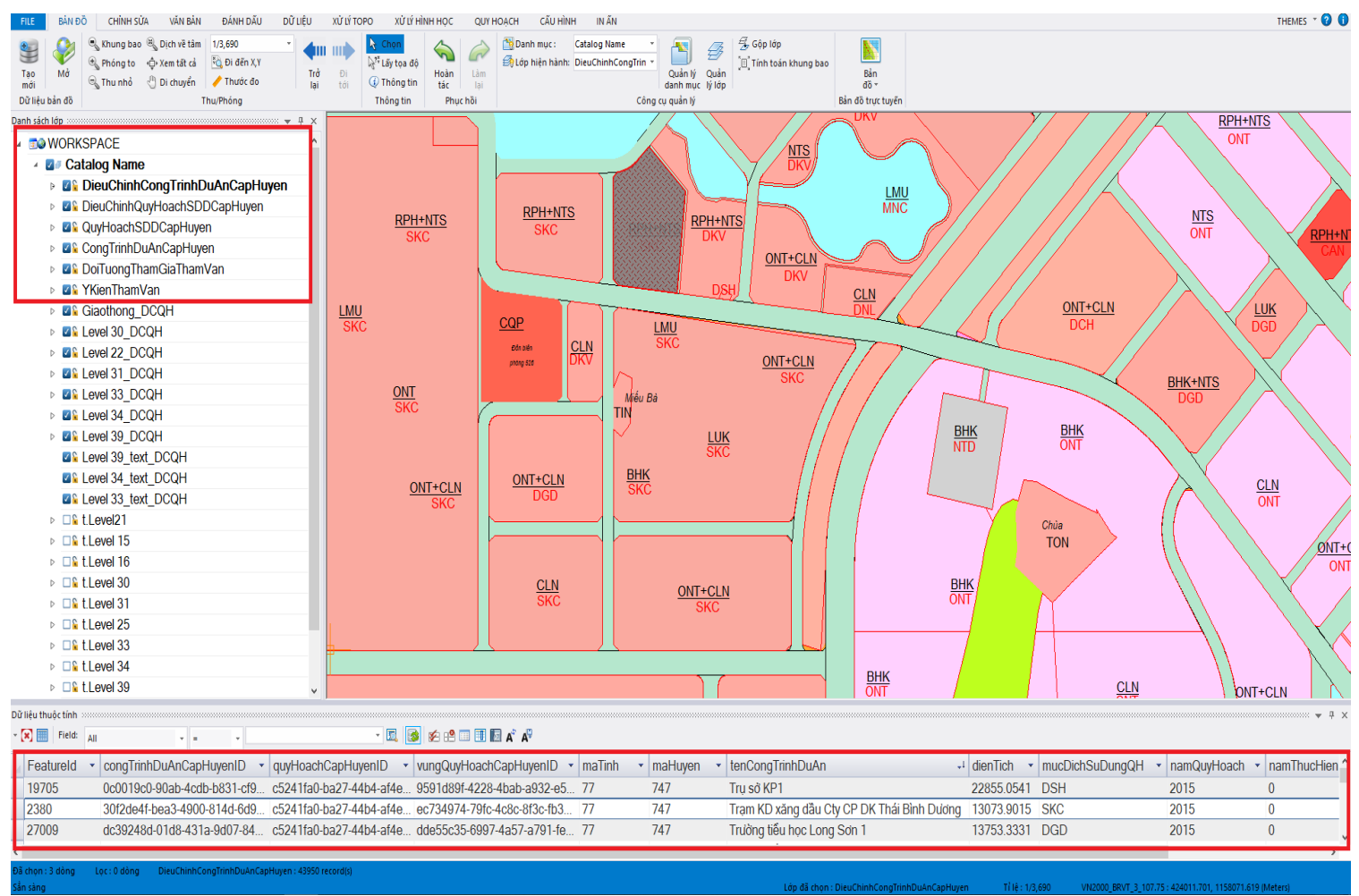

Hình 10. Kết quả xây dựng cơ sở dữ liệu quy hoạch sử dụng đất TP. Vũng Tàu trên VBDLIS. 


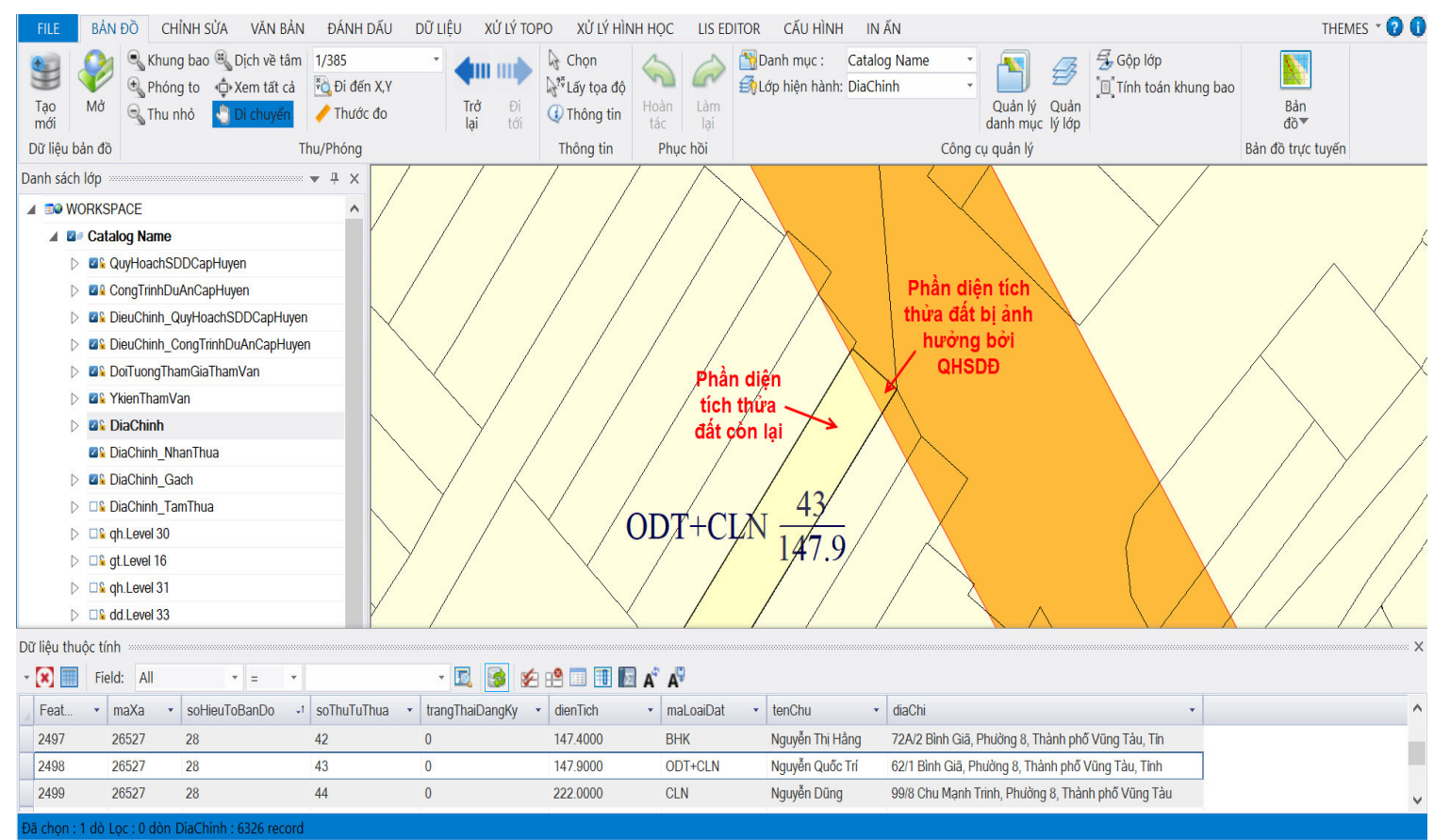

圈 Dữ liệu thuộc tính 国 Tập lệnh Xem vết

Hình 11. Kết quả tham chiếu cơ sở dữ liệu quy hoạch sử dụng đất tới cơ sở dữ liệu địa chính Phường 8 , TP. Vũng Tàu.

thửa đất bị ảnh hưởng bởi phương án quy hoạch như tên chủ, số hiệu thửa đất, địa chỉ, diện tích và mục đích sử dụng hiện trạng của thửa đất đó; giúp quá trình khai thác và truy vấn thông tin QHSDĐ toàn diện và đầy đủ hơn, đáp ứng nhu cầu của cơ quan, đơn vị, người dân và doanh nghiệp trong giao dịch đất đai và tra cứu thông tin QHSDĐ.

\subsubsection{Quản lý, cập nhật, chia sẻ và khai thác cơ sở dữ liệu quy hoạch sử dụng đất}

Để thực hiện tốt việc quản lý, cập nhật, chia sẻ, khai thác CSDL QHSDĐ và tích hợp CSDL QHSDĐ vào CSDL đất đai của TP. Vũng Tàu, cần thiết phải xây dựng thành công hệ thống thông tin (HTTT) QHSDĐ nói riêng và HTTT đất đai nói chung cùng với phần mềm quản lý, vận hành phù hợp. Tuy nhiên, do giới hạn về kinh phí và thời gian thực hiện, đề tài chỉ có thể dừng ở đề xuất giải pháp và mô hình thực hiện cho hai nội dung này.

Theo MONRE (2015), CSDL QHSDĐ là một thành phần quan trọng trong 8 thành phần cấu thành nên CSDL đất đai. Do vậy, việc quản lý, cập nhật, khai thác và chia sẻ CSDL QHSDĐ buộc phải được thực hiện dựa trên quy định về quản lý, vận hành và khai thác thác HTTT đất đai của ngành. Vì vậy, đề tài đề xuất mô hình tổng thể HTTT đất đai cho tỉnh BR - VT như Hình 12. Theo đó, CSDL đất đai toàn tỉnh sẽ được quản lý tập trung tại Sở Tài nguyên \& Môi trường. CSDL này sẽ được khai thác bởi phần mềm HTTT đất đai thống nhất chung của cả tỉnh; đồng thời, kết nối với các cấp, các cơ quan, đơn vị và đối tượng có nhu cầu thông qua môi trường điện toán đám mây (Cloud Computing) để thực hiện các công việc liên quan đến cập nhật, xử lý, quản lý và chia sẻ dữ liệu đất đai, như: Quản trị hệ thống; Quản trị người sử dụng; Quản lý điều hành công việc; Quản lý quy trình ISO; Cập nhật, xử lý dữ liệu; Trao đổi, chia sẻ dữ liệu; Thực hiện các dịch vụ qua Cổng dịch vụ công đất đai; Tra cứu, cung cấp thông tin đất đai; và Thực hiện các dịch vụ đất đai khác.

\section{a. Quản lý, cập nhật và chia sẻ cơ sở dữ liệu quy hoạch sử dụng đất}

Về quản lý CSDL QHSDĐ: CSDL QHSDĐ tỉnh BR - VT được quản lý tập trung tại Sở Tài nguyên \& Môi trường và phân cấp quản lý cho các đơn vị trực thuộc và các Phòng Tài nguyên \& Môi trường; đồng thời, được theo dõi, giám 


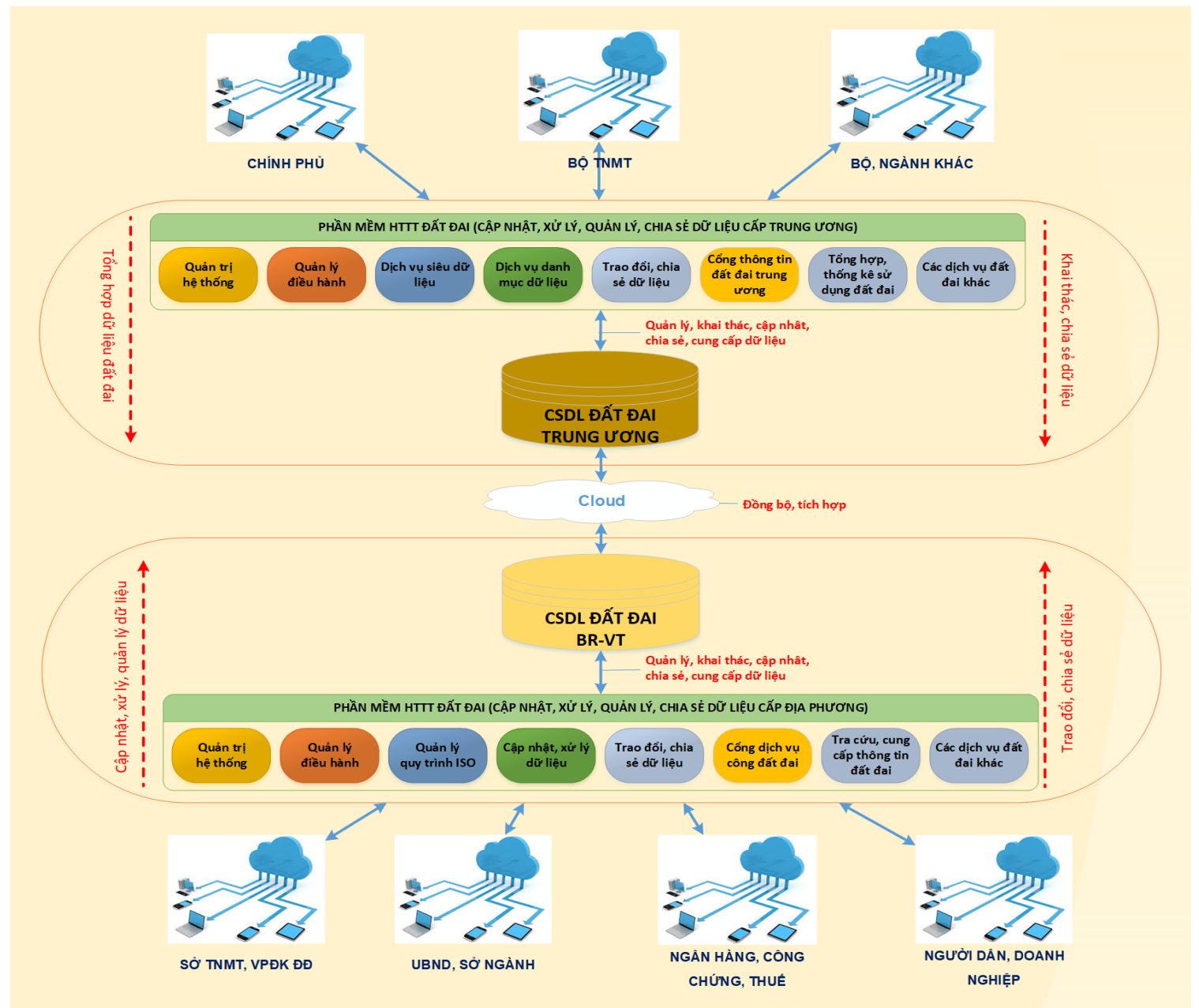

Hình 12. Mô hình tổng thể hệ thống thông tin đất đai tỉnh Bà Rịa - Vũng Tàu.

sát, đảm bảo hoạt động thông suốt và sao lưu dự phòng thường xuyên.

Về Quản trị người sử dụng: Tài khoản người sử dụng để truy cập vào CSDL QHSDĐ do Sở Tài nguyên \& Môi trường cấp. Các đơn vị, tổ chức khác có nhu cầu sẽ được cấp tài khoản theo đề nghị bằng văn bản. Người dân, doanh nghiệp có nhu cầu truy cập cần đăng ký tài khoản trên cổng thông tin điện tử của Sở Tài nguyên \& Môi trường để được cấp tài khoản tra cứu, khai thác thông tin quy hoạch. Mỗi đối tượng tài khoản người dùng nêu trên sẽ được phân quyền truy cập theo thẩm quyền quản lý, theo chức năng sử dụng, khai thác theo phạm vi dữ liệu.

Về cập nhật CSDL QHSDĐ: CSDL QHSDĐ TP. Vũng Tàu sẽ được Phòng Tài nguyên \& Môi trường cập nhật theo kết quả điều chỉnh trong kỳ hoặc kết quả lập QHSDĐ của kỳ tiếp theo sau khi được cơ quan có thẩm quyền phê duyệt. Thông tin cập nhật phải dầy đủ, thống nhất đồng thời trên các khối dữ liệu gồm: dữ liệu không gian, dữ liệu thuộc tính, dữ liệu hồ sơ quét tương ứng với kết quả thẩm định QHSDĐ theo quy định và được thiết lập chế độ bảo vệ (chỉ cho phép đọc) sau khi kết thúc quy trình. Ngoài ra, các ý kiến về TVCĐ cũng có thể được tiếp tục tiếp thu và xử lý thông qua các hình thức theo mô hình CSDL thuộc tính QHSDĐ đã được thiết kế tại mục 3.2.2.

Về chia sẻ CSDL QHSDĐ: CSDL QHSDĐ được chia sẻ thông qua 02 hình thức, gồm: chia sẻ dữ liệu mặc định và chia sẻ dữ liệu theo yêu cầu đặc thù. Ngoài ra, khi xây dựng HTTT cần bảo đảm tính mở, cho phép chia sẻ với HTTT và CSDL của các ngành khác và các cấp có liên quan. Đồng thời, các cơ quan quản lý CSDL, cơ quan được 


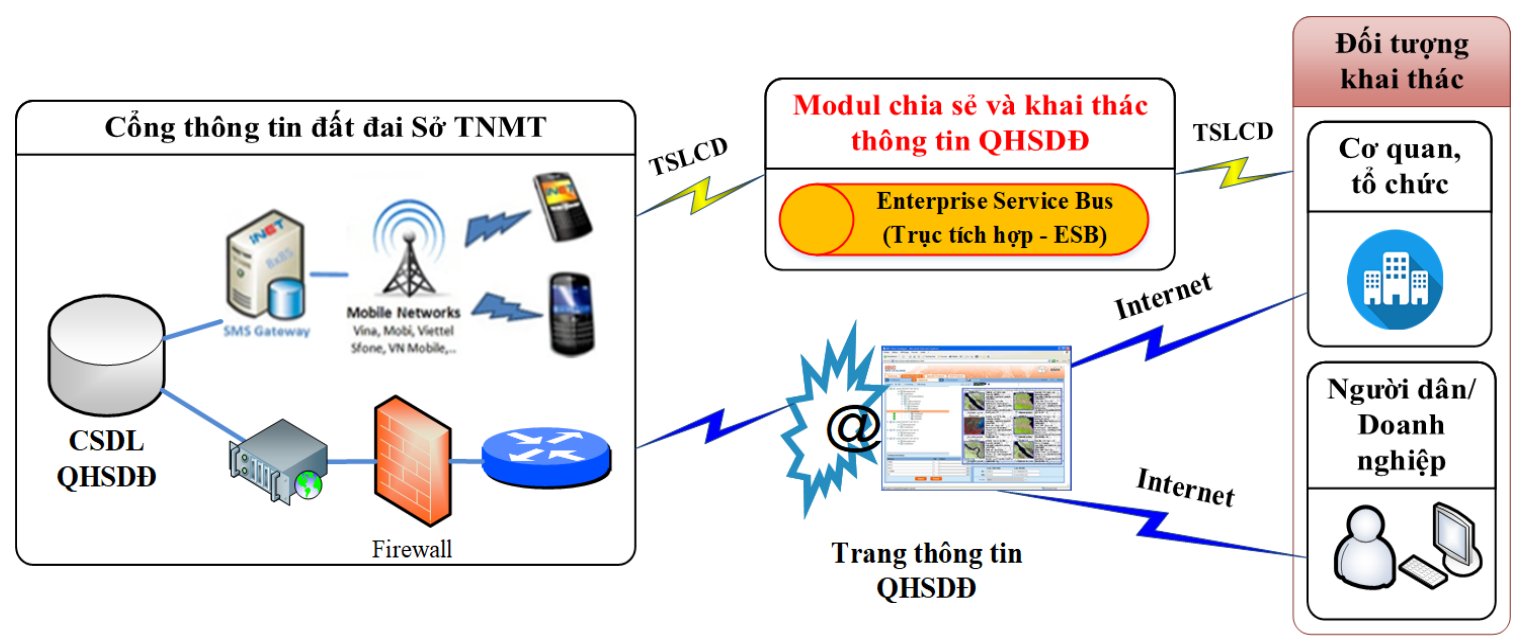

TSLCD Hệ thống mạng truyền số
Internet

Z Hệ thống mạng Internet công cộng: ADSL, vDSL, FTTH,...

Hình 13. Mô hình khai thác thông tin quy hoạch sử dụng đất (MONRE, 2020).

chia sẻ dữ liệu cần có trách nhiệm áp dụng các biện pháp nghiệp vụ - kỹ thuật cần thiết bảo đảm sự chia sẻ dữ liệu an toàn, chính xác, kịp thời (Gov, 2020).

b. Khai thác cơ sở dữ liệu quy hoạch sử dụng đất

Để CSDL QHSDĐ được khai thác hiệu quả, Sở Tài nguyên \& Môi trường cần xây dựng hệ thống hạ tầng kỹ thuật, phần mềm, cổng thông tin phục vụ việc chia sẻ, khai thác dữ liệu, thông tin về QHSDĐ chung của cấp tỉnh và cấp huyện (Hình 13).

Theo đó, các cơ quan, tổ chức nhà nước và các cá nhân, tổ chức khác có nhu cầu khai thác dữ liệu, thông tin QHSDĐ từ Cổng thông tin đất đai của tỉnh có thể khai thác thông tin thông qua các hình thức: (1) Khai thác thông qua việc chia sẻ, trao đổi thông tin giữa hệ thống phần mềm chuyên ngành của đơn vị với HTTT QHSDĐ của Sở Tài nguyên \& Môi trường; và (2) Khai thác thông tin đất đai qua mạng internet, cổng thông tin đất đai, dịch vụ tin nhắn SMS.

3.4.3. Tích hợp cơ sở dữ liệu quy hoạch sử dụng đất vào cơ sở dữ liệu đất đai TP. Vũng Tàu

Việc tích hợp CSDL QHSDĐ được thực hiện theo quy định tại Thông tư số 05/2017/TTBTNMT của Bộ Tài nguyên \& Môi trường và phải đảm bảo cho việc vận hành tại địa phương (Hình 14).
Ngoài ra, để tích hợp CSDL đất đai cấp tỉnh vào $\mathrm{HTTT} / \mathrm{CSDL}$ đất đai quốc gia, Bộ Tài nguyên \& Môi trường cần xây dựng Hệ thống kết nối, chia sẻ CSDL quốc gia thông qua tổ chức phối hợp với Bộ Thông tin và Truyền Thông cùng các cơ quan Tài nguyên \& Môi trường ở địa phương, nhằm tích hợp các nguồn CSDL đất đai do trung ương xây dựng, quản lý, cập nhật với các nguồn CSDL đất đai cho các tỉnh, thành phố trực thuộc trung ương xây dựng, quản lý, cập nhật vào CSDL đất đai quốc gia để phục vụ việc kết nối, chia sẻ dữ liệu trực tuyến với các HTTT/ CSDL quốc gia, của các Bộ, Ngành, Địa phương thông qua nền tảng tích hợp, chia sẻ dữ liệu cấp Bộ, cấp Tỉnh (LGSP); nền tảng tích hợp, chia sẻ dữ liệu quốc gia (NGSP); Cổng Dịch vụ công quốc gia; Cổng Dữ liệu quốc gia; hoặc Cung cấp dữ liệu trực tiếp...

\subsection{Hướng phát triển của vấn đề nghiên cứu}

Do bị giới hạn về kinh phí và thời gian thực hiện nên trong phạm vi cho phép của đề tài này, tác giả chỉ dừng ở nghiên cứu 4 nội dung chính nêu trên. Từ các kết quả này, để xây dựng thành công CSDL QHSDĐ và tiến đến hoàn chỉnh CSDL đất đai cho TP. Vũng Tàu phù hợp và đồng bộ với CSDL đất đai cả nước, cần tiến hành nghiên cứu mở rộng các nội dung sau: (1) Đánh giá công tác TVCĐ trong quá trình lập và triển khai phương án QHSDĐ tại TP Vũng Tàu; (2) Triển khai thu 


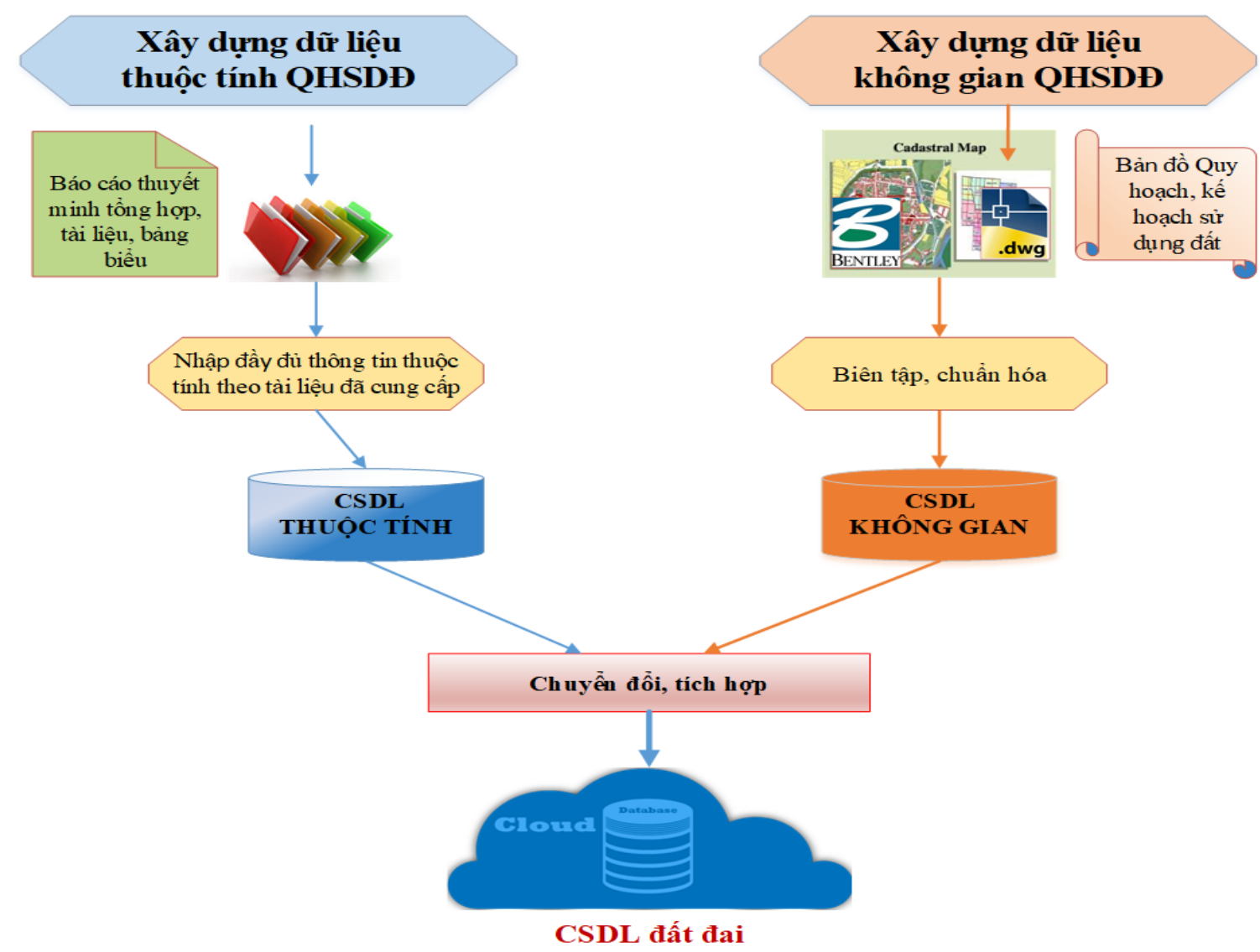

Hình 14. Mô hình tích hợp cơ sở dữ liệu quy hoạch sử dụng đất vào cơ sở dữ liệu đất đai.

thập ý kiến cộng đồng và xây dựng công cư hỗ trợ thu thập, tổng hợp, xử lý thông tin TVCĐ phục vụ hoàn chỉnh các lớp dữ liệu về TVCĐ trong lập và quản lý QHSDĐ cho TP. Vũng Tàu; (3) Quản lý, khai thác và chia sẻ CSDL QHSDĐ TP. Vũng Tàu; và (4) Tích hợp CSDL QHSDĐ TP. Vũng Tàu vào CSDL đất đai của địa phương và đề xuất mô hình quản lý, khai thác phù hợp.

\section{Kết Luận}

Nghiên cứu đã thiết kế được mô hình CSDL QHSDĐ (có đề cập đến yếu tố tham vấn cộng đồng) cho TP. Vũng Tàu theo đúng quy chuẩn dữ liệu đất đai của Thông tư 75/2015/TT-BTNMT và nhu cầu thực tế trong công tác QLĐĐ tại địa phương. Qua đó, các thực thể trong mô hình CSDL không gian lẫn thuộc tính QHSDĐ được biểu diễn rõ ràng và chặt chẽ hơn nhờ các quan hệ liên kết, cũng như cấu trúc CSDL được thể hiện rõ hơn ứng với từng trường dữ liệu cụ thể. Trên cơ sở đó, đề tài đã xây dựng thành công bộ cấu trúc CSDL QHSDĐ với 22 bảng dữ liệu không gian trên phần mềm ArcGIS và 8 bảng dữ liệu thuộc tính (có đề cập đến yếu tố TVCĐ) trên Hệ quản trị Microsoft SQL Sever; giúp quá trình truy xuất dữ liệu giữa các bảng được thực hiện khoa học, tường minh và nhanh chóng hơn. Cuối cùng, để kiểm chứng độ chính xác và hiệu quả của bộ cấu trúc CSDL, đề tài đã sử dụng phần mềm VBDLIS thử nghiệm xây dựng thành công CSDL quy hoạch sử dụng đất giai đoạn 2010 - 2020 (có đề cập đến yếu tố tham vấn cộng đồng) cho TP. Vũng Tàu với: 15.060 bản ghi thuộc lớp QHSDĐ, 163 bản ghi thuộc lớp Công trình dự án, 12.002 bản ghi thuộc lớp Điều chỉnh QHSDĐ, 570 bản ghi thuộc lớp Điều chỉnh công trình dự án và 2 lớp dữ liệu thuộc tính về TVCĐ (gồm: Lớp Đối tượng tham gia tham vấn, Lớp Ý kiến tham vấn); đồng thời, đề xuất các phương thức giúp quản lý, cập nhật, chia sẻ, khai thác CSDL quy hoạch sử dụng đất và tích hợp CSDL QHSDĐ vào CSDL đất đai của TP. Vũng Tàu. Kết quả đạt được cho thấy bộ cấu trúc CSDL quy hoạch sử dụng đất 
có độ chính xác cao, hoàn toàn phù hợp với quy chuẩn của ngành và mô hình CSDL đã được thiết kế. Theo đó, cơ sở dữ liệu quy hoạch sử dụng đất được xây dựng trên cơ sở dữ liệu không gian dất đai nền, được tham chiếu đến cơ sở dữ liệu địa chính, và được tích hợp với các bảng dữ liệu hỗ trợ tổng hợp và xử lý ý kiến tham vấn cộng đồng trong quá trình lập và quản lý quy hoạch sử dụng đất, đáp ứng yêu cầu đánh giá quy hoạch, phản hồi thông tin,... góp phần tăng tính khả thi cho phương án quy hoạch sử dụng đất cũng như tăng tính công khai, minh bạch trong quá trình giao dịch đất đai và tra cứu thông tin quy hoạch của người dân.

\section{Lời Cảm Ơn}

Kết quả này thuộc một phần đề tài khoa học và công nghệ cấp cơ sở "Nghiên cứu xây dựng mô hình cơ sở dữ liệu quy hoạch sử dụng đất có đề cập đến yếu tố yếu tố tham vấn cộng đồng tại thành phố Vũng Tàu, tỉnh Bà Rịa - Vũng Tàu", mã số: CS-CB20-QLDD-01 do Trường Đại học Nông Lâm TP.HCM làm chủ quản.

\section{Tài Liệu Tham Khảo (References)}

Chu, T. V., Nguyen, B. D., Nguyen, H. Q., Chu, T. A., Nguyen, H. D., \& Nguyen, H. T. T. (2020). Land use planning. Ha Noi, Vietnam: Vietnam Publishing House of Natural Resources, Environment and Cartography.

Gov (Government). (2020). Decree of 47/2020/ND-CP dated April 09, 2020. Managing, connecting and sharing digital data of state agencies. Ha Noi, Vietnam: Government Office. Retrieved April 09, 2020, from http://vanban.chinhphu.vn/portal/page/portal/chinh $\mathrm{phu} /$ hethongvanban?class_id $=1 \&$ _page $=19 \&$ mode $=$ detail\&document_id $=199 \overline{7} 54$.
LeBlanc, P. (2013). Microsoft SQL Server 2012 step by step. London, UK: Pearson Education.

MOHA (Ministry of Home Affairs). (2016). Increasing people's participation in state management activities. Retrieved May 30, 2021, from https://tcnn.vn/news/ detail/4560/Tang_cuong_su_tham_gia_cua_nhan dan_trong_hoat_dong_quan_ly_nha_nuocall.html.

MONRE (Ministry of Natural Resources and Environment). (2020). Circular of 06/VBHN-BTNMT dated August 07, 2020. Regulations on construction, management and exploitation of land information systems. Ha Noi, Vietnam: MONRE Office.

MONRE (Ministry of Natural Resources and Environment). (2015). Circular of 75/2015/TT-BTNMT dated December 28, 2015. Technical regulation about land databases. Ha Noi, Vietnam: MONRE Office.

NA (National Assembly). (2018). Law of 35/2018/QH14 dated November 20, 2018. Amending and supplementing some articles of 37 laws related to planning. Ha Noi, Vietnam: National Assembly Office.

Nguyen, K. T. (2015). The current situation and solutions to strengthen community consultation in land management in Luong Son district, Hoa Binh province (Unpublished doctoral dissertation). Vietnam National University of Agriculture, Ha Noi, Vietnam.

Nguyen, K. T., Nguyen, B. D., \& Do T. T. (2014). Community consultation in land management in Hoa Binh province. Vietnam Journal of Soil Science 2014(43), 181-184.

OIV (Oxfam in Vietnam). (2013). A report on public consultation for the 2013 draft land law amendment. Retrieved April 1, 2021, from https://oxfamblogs.org/ vietnam/wp-content/uploads/2013/06/Executive-sum mary_TV-29-May-Final.pdf.

Truong, L. D. T. (2021). Land database lecture. Nong Lam University, Ho Chi Minh City, Vietnam. 